\title{
VIVÊNCIAS E SIGNIFICAÇÕES SOCIOAMBIENTAIS DO PROJETO HORTO MUNICIPAL DE FAXINAL DO SOTURNO/RS
}

\author{
Juliana Andreola ${ }^{1}$, Jumaida Rosito ${ }^{2}$ \\ ${ }^{1}$ Aluna Curso de Pós- Graduação em Educação Ambiental, UFSM. \\ ${ }^{1}$ Professora Orientadora, Dra Jumaida Rosito, UFSM.
}

\section{Resumo}

Este trabalho foi desenvolvido no contexto do Programa de Atenção Integral a Criança e ao Adolescente, Horto Municipal de Faxinal do Soturno/RS. Este programa social recebe crianças e adolescentes do município, que se encontram em situação de vulnerabilidade social. O objetivo do trabalho foi verificar se o Programa contribui para o despertar da conscientização ambiental entre as crianças e adolescentes participantes, e, além disso, procurou-se conhecer o significado social do convívio dos jovens com o projeto Horto. Para isso, nesta pesquisa utilizou-se a técnica de campo exploratória e incluiu análise qualitativa, através da utilização de questionários enviados às famílias e relatos dos jovens atendidos pelo projeto, sobre suas vivências no Horto. Os resultados evidenciaram que o projeto do Horto Municipal é percebido como um ambiente de socialização, convivência, construção da aprendizagem, e, fundamentalmente, incentivador de valores que se relacionam a práticas preservacionistas ambientais. Com isso pode-se afirmar que, além de alcançar seus objetivos principais, o projeto contribui para a formação de cidadãos conscientes de suas ações com o meio ambiente.

Palavras-chave:Projeto Horto Municipal; Educação Ambiental; Conscientização Ambiental; Praticas Socioambientais.

\begin{abstract}
This research was developed in the context of Integral Attention to Children and Adolescents' Program, in Faxinal Soturno/RS' Garden. This social program receives children and adolescents of the city, which are in a social vulnerability situation. The objective of this study was to examine if the program contributes to the awakening of environmental awareness among children and adolescents, and, moreover, it sought to know the meaning of the social interactionbetween youngs in the the Garden's Project. For this, in this research was used the technique of field exploratory and included the qualitative analysis through the use of questionnaires, those was sent to families and reports obtained with youth those are participante of the project, that relate theirs experiences in the Garden. The results shows that the Project of the Garden is perceived as an environment for socialization, interaction, construction of learning, and fundamentally stimulator of values that they are connect with the environmental preservationists practices. With this, it can be said that the project reach your main objectives and the same time it contributes to the formation of citizens aware of their actions with the environment.
\end{abstract}


Keywords: Municipal Garden Project, Environmental Education,Environmental Awareness, Social and Environmental Practices.

\section{Introdução}

Em 1993 teve início o desenvolvimento de um programa social junto à Granja Municipal de Faxinal do Soturno (RS), o "Programa da Criança e do Adolescente", onde meninos que provinham de famílias que se encontravam em situação de vulnerabilidade social também poderiam participar do projeto.

Hoje, esse projeto que atende a 45 crianças e adolescentes entre oito e dezoito anos, e que freqüentam o espaço no turno inverso ao da escola, recebe a denominação de "Programa de Atenção Integral à Criança a ao Adolescente, Horto Municipal". Ele estimula, da mesma forma, o envolvimento dos familiares nas ações propostas (Prefeitura Municipal de Faxinal do Soturno/RS, 2005). Esse Programa busca proporcionar um espaço de referência à crianças e adolescentes que se encontram em situação de vulnerabilidade social, e que são encaminhados pelo Conselho de Direitos da Criança e do Adolescente, Conselho Tutelar, Poder Judiciário, Assistente Social do município ou por demanda voluntária da própria família. Conta com o suporte das Secretarias Municipais da Agricultura, Assistência Social e Habitação, com a parceria da Associação RioGrandense de Empreendimento e Assistência Técnica de Extensão Rural (EMATER) e do Conselho Tutelar de Faxinal do Soturno.

Nesse espaço são oportunizadas às crianças e adolescentes oficinas que vão desde noções de cidadania, de cultivo de hortaliças, jardinagem, culinária alternativa, noções básicas de agricultura e áreas afins como suinocultura, pecuária, avicultura, até atividades que contemplem o esporte, atividades culturais, artísticas e recreativas. Além disso, é disponibilizada aos meninos participantes deste projeto social do Horto, uma bolsa de estudo mensal e almoço diário; também são disponibilizadas às famílias parte do que é cultivado no espaço do projeto do Horto Municipal.

Diante do exposto, esse trabalho teve como principal preocupação verificar se o Projeto ajuda a despertar a conscientização ambiental entre as crianças e adolescentes atendidos, e, além disso, buscar conhecer o significado social do convívio dos jovens com o projeto do Horto.

Esta avaliação foi feita através de questões levadas aos pais e/ou responsáveis e através do relato de vivências (das crianças e adolescentes) no Horto, incentivado pela elaboração de histórias que marcaram cada uma das crianças e adolescentes.

Paralelo a isso, espera-se dar visibilidade à função socioambiental do Horto, através da concretização de um livro coletivo com o relato das vivências dos participantes do projeto, com as vivências e significações que essa experiência agrega a cada um.

\section{Educação Ambiental e Conscientização}

O contexto da escola é um dos lugares mais propícios para trabalhar com a questão do ambientalismo. Isso porque é nela que estão reunidos e se formam os futuros cidadãos que, na escola, poderão passar pelo trabalho de conscientização desde a primeira infância.

Essa conscientização condiz com as atitudes que estes futuros cidadãos terão com o espaço, possibilitando a garantia de uma vida digna para as futuras gerações, uma vez que os 
gestos e ações de hoje no ambiente serão refletidos no futuro do nosso Planeta. Para Morin (2000, p. 76), “(...) é necessário aprender "estar aqui" no planeta. Aprender a estar aqui significa: aprender a viver, a dividir, a comunicar, a comungar (...)".

Assim, se considerarmos que a educação ambiental é também formadora de cidadania, é possível inferir que todos somos os responsáveis por uma conscientização ambiental. Com isso, podemos destacar que além do contexto escolar, os diferentes espaços da nossa sociedade podem ser entendidos e ocupados como os disseminadores de propostas teóricas educacionais ambientais.

A Educação Ambiental é uma educação crítica da realidade, participativa, criativa, formadora de cidadania. É transformadora de valores e atitudes através da construção de novos hábitos e conhecimentos, criadora de uma nova ética, sensibilizadora para as relações integradas ser humano/sociedade/natureza objetivando o equilíbrio social e global como forma de obtenção da melhoria da qualidade de todos os níveis da vida (GUIMARÃES, 1995, p.28).

Desta maneira, trabalhar com as crianças e adolescentes as questões que se relacionam à preservação ambiental é apostar no futuro caracterizado pela esperança de um Planeta mais preservado. Com isso, é depositado nos jovens e nas crianças de hoje a esperança de um futuro para um planeta mais 'saudável' de estar. Talvez isso aconteça principalmente através do processo de conscientização, do despertar do olhar para a manutenção do meio, e portanto se possa contribuir para a formação de futuros cidadãos que venham causar menores impactos ambientais.

\section{Metodologia}

Esse trabalho foi desenvolvido no contexto do projeto Horto Municipal de Faxinal do Soturno (RS). O público-alvo foram crianças e adolescentes, bem como famílias e demais profissionais que estão, de alguma maneira, diretamente ligados ao "Programa de Atenção Integral à Criança e ao Adolescente, Horto Municipal".

A técnica de pesquisa utilizada foi a pesquisa de campo exploratória (LAKATOS; MARCONI, 2007) e, em função de suas peculiaridades, esta pesquisa teve uma abordagem qualitativa.

Para a coleta de dados e resultados, fez-se uso de questionários, bem como de relatos (dos participantes) com relação a sua experiência no espaço do Horto.

Os questionários foram enviados para 38 famílias no mês de agosto de 2011, através dos alunos atendidos nas aulas apoio pedagógico escolar. Os alunos foram esclarecidos sobre os objetivos da pesquisa e conscientizados sobre a importância de sua participação e de suas famílias. Com relação aos relatos, foi solicitado que falassem sobre há quanto tempo participam, sobre suas atividades favoritas e sobre as questões que lhes parecem mais ligadas ao meio ambiente. Na transcrição desses relatos, nesse trabalho, foram feitas algumas correções ortográficas.

\section{Resultados e Discussões}

Do total de 38 questionários enviados às famílias, 30 foram respondidos, e foram a base para os resultados apresentados a seguir. 
Nessas famílias, as crianças atendidas tinham idades que variaram de nove a dezessete anos. Ressalte-se que o projeto é aberto a crianças e adolescentes do sexo masculino, com idade entre oito e dezoito anos.

Em relação ao tempo de inclusão dessas crianças no projeto, todas estão participando há pelo menos um ano, sendo que quase a metade delas (14 crianças), são atendidas há mais de dois anos.

Pela análise dos questionários apresentados, parece evidente que a preocupação social é uma das grandes incentivadoras das famílias, com relação à participação das crianças no projeto. Mais da metade das famílias (16) mencionou a preocupação com a segurança e aprendizagem, como questão motivadora de inserção de seu filho nas atividades do Horto. Isso pode ter relação direta com o temor pelos perigos que as ruas oferecem às crianças, pois, é fato notório nessa comunidade, o consumo de droga e álcool, bem como aspectos relacionados a isso.

Quando o questionamento tenta estabelecer um vínculo entre a criança, suas vivências e o grupo familiar, constatou-se que metade dos entrevistados afirma que as crianças falam sempre ou frequentemente com o grupo familiar, sobre as atividades desenvolvidas no projeto. Esses dados demonstram que existe um diálogo entre os pais e seus filhos sobre as práticas desenvolvidas dentro do espaço do Horto. Além disso, mostra que grande parte dos envolvidos com o projeto se sente de alguma forma foram tocados pelas atividades desenvolvidas. Além disso, constatou-se que, 27 das 30 familias entrevistadas afirma que as crianças demonstram interesse em aplicar em seu grupo de convivência, práticas aprendidas no Horto.

Quando questionados sobre possíveis mudanças positivas ou estímulos percebidos em seus filhos, depois da participação no projeto, a maioria das famílias aponta que as crianças tornaramse mais sociáveis, responsáveis e alunos melhores. $O$ aumento na capacidade de concentração e a maior tranqüilidade também foram mencionados por algumas famílias como ganho advindo da participação no projeto.

Com relação a esta questão, Coll (1994) traz a idéia de que a interação social pode contribuir para a vida da criança, pois:

$\mathrm{Na}$ interação social, a criança aprende a regular os seus processos cognitivos, seguindo as indicações e diretrizes dos adultos, produzindo-se um processo de interiorização mediante o qual o que pode fazer ou conhecer a princípio com a ajuda deles (...) transforma-se progressivamente em algo que pode fazer ou conhecer por si mesmo (...) (COLL, 1994,p. 93).

A responsabilidade e organização são outros dois pontos que também foram despertados nos participantes e, tanto as famílias notaram essa característica em seus filhos, como eles mesmos. Os quatro relatos a seguir deixam isso explícito:

Aprendi a ser organizado porque tem que lavar e guardar as ferramentas direitinho. Aprendi a ter responsabilidade ( $L E, 14$ anos).

No Horto eu aprendo a ter responsabilidade porque cada ferramenta que nós ocupamos temos que lava-las e guardá-las (W X,13 anos).

É importante mencionar também, considerando a preocupação do projeto Horto com a questão ambiental, que metade das famílias aponta um aumento de entusiasmo de seus filhos com assuntos relacionados às plantas. Além disso, em outra questão abrangendo esse assunto, 
todas as famílias afirmaram que o contato com o Horto incentivou de algum modo, seus filhos terem maior cuidado com o meio ambiente e com os animais.

Esta constatação demonstra que as práticas desenvolvidas no projeto estão sendo positivas e motivadoras da conscientização ambiental, que o projeto do Horto consegue conquistar e sensibilizar para o contato e o cuidado com tudo o que se refere ao meio ambiente.

Grande parte dos meninos mencionou ainda que, no Horto, aprenderam a cultivar, semear, plantar, cuidar, preservar. Todas estas práticas são ligadas às próprias ações que devemos ter para com este espaço que vivemos, a natureza. A seguir, um dos relatos que comprova esse aprendizado:

Eu faço várias coisas no horto, várias dessas coisas ajudam o meio ambiente. Plantamos árvores nos locais desmatados, limpamos todo dia as plantas da cidade. Podamos as árvores que ficam próximas das fiações para não dar incêndio e cuidamos das avenidas para ficarem bonitas.

Aprendemos como cuidar da natureza, aprendemos a não matar as árvores e fazer mudas de árvores. (E,17 anos).

Nesse sentido, podemos entender que estas praticas acabam também tendo relação direta com os aspectos que se relacionam a educação ambiental. Díaz (2002) pode nos ajudar nesta relação, principalmente quando escreve que

A finalidade da educação ambiental é, de fato, levar à descoberta de uma certa ética, fortalecida por um sistema de valores, atitudes, comportamentos, destacando, entre os primeiros, questões como a tolerância,(...) ou a responsabilidade ( DÍAZ,2002, p.37).

Também é possível notar que algumas crianças conquistaram e construíram uma relação de amor entre eles, as plantas, e o espaço do Horto. Ao comentarem em seus relatos sobre a importância em cuidar do meio ambiente, deixam transparecer que o que fazem no ambiente do Horto é feito com muito amor e se tudo o que é feito lá está relacionado principalmente ao cuidado das plantas e animais, é possível inferir que eles cuidam por amar. Essa questão pode ser ilustrada com os seguintes relatos:

Nós cuidamos as árvores do Horto (...). (V R, 10 anos).

Eu aprendo a cuidar das plantinhas e limpo o Horto. (M, 12 anos).

$E$, além deste sentimento de amorosidade, é importante notar, também, que os participantes do projeto do Horto Municipal de Faxinal do Soturno, sentem-se comprometidos com as atividades, são responsabilizados pelos cuidados com o meio ambiente e por todo o trabalho realizado naquele espaço. Isso é muito importante, pois, como comenta Trigueiro (2008), a maioria dos brasileiros não se percebe como seres inseridos no espaço natural do meio ambiente. $E$, segundo o autor, a conscientização ambiental ocorre na exata proporção em que percebemos meio ambiente como algo que começa dentro de cada um de nós, alcançando tudo o que nos cerca e as relações que estabelecemos com o universo.

Nesta pesquisa ainda, o questionário convidou as famílias a darem sugestões de atividades relacionadas ao meio ambiente e que poderiam ser desenvolvidas por seus filhos no espaço do Horto. Foram mencionadas a reciclagem, enxertia, pesca, entre outras atividades que poderiam ser desenvolvidas no espaço do Horto. Essa atitude, deixa implícito o interesse das famílias proporcionar a seus filhos conhecimento que seja relacionado ao próprio meio em que vivem, e que serão experiências que levarão consigo para toda vida. 
Nesse sentido, tem-se suporte nas idéias de Layrargues (2000, apud LOUREIRO e LAYRARGUES, 2000, p.157), que diz que a questão ambiental deixa de ser uma preocupação apenas dos profissionais que estão diretamente ligados à questão ambiental, uma vez que "vemos atualmente que esse tema envolve todos, uma vez que cada um de nós está sujeito aos efeitos dos problemas ambientais, tanto regionais quanto globais".

Todos os familiares respondem que o contato de seus filhos com o projeto os tornou mais sensíveis nas suas ações com o meio ambiente. Este fato associado às sugestões de atividades mencionadas, reflete a preocupação com o espaço natural. Isso pode ser comprovado principalmente quando sugerem que o projeto desenvolva mais práticas de reciclagem e produção de adubo orgânico a partir de minhocas, e ainda o incentivo quanto ao cuidado com as plantas da Vila (local onde residem). Assim, é evidente a constatação que o projeto também consegue sensibilizar as famílias dos envolvidos, no que tange ao cuidado com o meio ambiente.

\section{Conclusão}

Os resultados evidenciaram que o projeto do Horto Municipal é percebido como um ambiente de socialização, convivência, construção da aprendizagem, e, fundamentalmente, incentivador de valores que se relacionam a práticas preservacionistas ambientais. Com isso podese afirmar que, além de alcançar seus objetivos principais, o projeto contribui para a formação de cidadãos conscientes de suas ações com o meio ambiente.

Pela riqueza dos dados coletados, a idéia da construção de um livro coletivo, com as histórias de vivências das crianças e adolescentes nesse espaço, desponta como uma forma de valorizar e dar visibilidade ao trabalho desenvolvido pelo Programa de Atenção Integral à Criança e ao Adolescente, Horto Municipal de Faxinal do Soturno. 


\section{Referências}

COLL, César. Aprendizagem Escolar e Construção do Conhecimento. Trad. Emília de Oliveira Dihel. Porto Alegre: Artmed, 1994.

DÍAZ, Alberto P. Educação Ambiental como projeto.Fátima Murad (trad.), 2a ed., Porto Alegre: artmed, 2002.

GUIMARÃES, Mauro. A dimensão ambiental na educação. 8a ed, São Paulo: Papirus, 1995, (Coleção; magistério formação e trabalho).

LAKATOS, Eva Maria; MARCONI, Marina de Andrade. Fundamentos da metodologia científica. 6 ed, São Paulo:Atlas, 2007.

LOUREIRO, Carlos; B., LAYRARGUES; Philippe P., CASTRO; Ronaldo S.. Sociedade e Meio Ambiente: a educação ambiental em debate. (orgs). São Paulo: Cortez, 2000.

MORIN, Edgar. Os sete saberes necessários à educação do futuro; (tradução de Catarina Eleonora F. da Silva e Jeanne Sawaya ; revisão técnica de Edgard de Assis Carvalho), 2. ed., São Paulo: Cortez; Brasília, DF: UNESCO, 2000.

PREFEITURA MUNICIPAL DE FAXINAL DO SOTURNO/RS. Secretaria do Meio Ambiente e da Agricultura. Regimento Interno do Horto Municipal. Faxinal do Soturno, 2005.

TRIGUEIRO, André. Meio Ambiente no século 21: 21 especialistas falam da questão ambiental nas suas áreas do conhecimento. (Autores associados), 5a ed.,Campinas, São Paulo:Armazén do Ipê, 2008. 